The European Journal of Social \& Behavioural Sciences (eISSN: 2301-2218)

\title{
Tradition VS Reform: A Critical Review of Teacher Evaluation Beliefs in China
}

\author{
Qiaoyan He ${ }^{\mathrm{a}, \mathrm{b}}$, Martin Valcke ${ }^{\mathrm{a}}$, Antonia Aelterman ${ }^{\mathrm{a}}$, Chang Zhu ${ }^{\mathrm{a}} *$ \\ ${ }^{a}$ Department of Educational Studies, Ghent University, Gent, B9000, Belgium \\ ${ }^{\mathrm{b}}$ School of Educational Science, Sichuan Normal University, Chengdu, 610101, China
}

\begin{abstract}
In context of Chinese New Evaluation reform devoting to change the negative aspects of traditional evaluation including evaluating aim, content, method and student-teacher relationship as well as testing system, we disclosed that the "top-to-down" political and educational system is the critical barrier to block the new theories putting into practice. In order to promote communication between top and down, this paper focuses on the evaluation (the driving force) to explore the relationship between teacher beliefs (why, what, who, when and how) in the classroom and the key problems of New Evaluation reform as "why-aim", "what-content", "who-student-teacher relationship", "how-method" and "when- time", and then explore some effective counter-measures to involve both top and down into harmony communication to promote Chinese education development.
\end{abstract}

(C) 2013 Published by C-crcs. Peer-review under responsibility of Editor or Guest Editor of the EJSBS.

Keywords: Chinese evaluation tradition; New evaluation reform; communication; teacher evaluation beliefs;

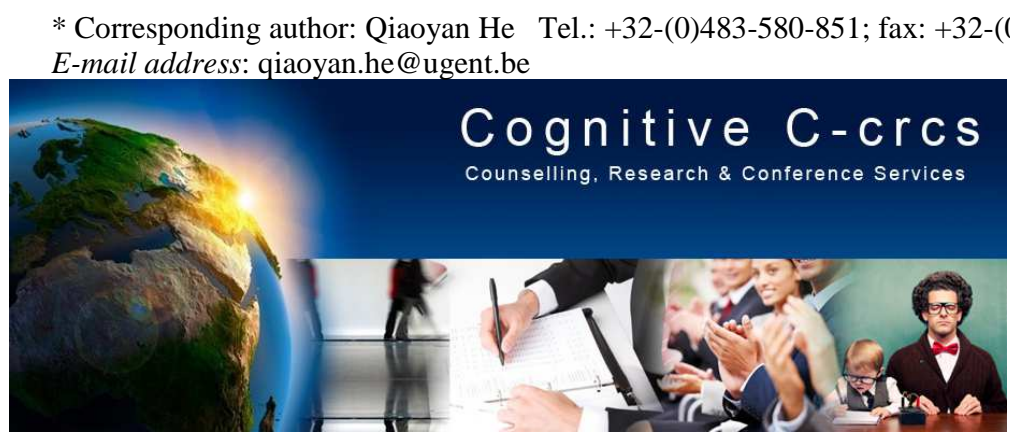




\section{Introduction:}

Educational tradition is an educational mode that has been passed by generations with stability, particularity and the long time nature among a region, a state or a nation (Zhang, 2005). It has been grown into people's beliefs and worldviews to influence their activities and environment (Hua, 2009). For that a teacher's beliefs are influenced by the classroom, students, the national policies, the cultural norms and values (Woolfolk \& Davis, 2006). However, educational tradition also influences teacher's actual practice in the classroom from the advantage and disadvantage effect. In order to improve educational progress, it is necessary for education to carry on a reform to conquer the negative barriers from tradition. During the evaluation reform taking place in China, researchers have been examining how beliefs influenced reactions to standards. Because these standards encouraged teachers to adopt ways of teaching they may not have experienced as students, their beliefs became screens for interpreting the new approaches. In order to understand teachers' beliefs relating to their practice as well as to student outcomes, we should see some missing link between calls for school reform and teachers' implementation of that reform (Gregoire, 2003). This idea was suggested to avoid the confliction between educational policies and classroom practice (Zhong, 2005; Wang, C., 2006; Wang, B., 2009). And it is the motivation for us discussing here to explore some countermeasures to promote evaluation reform to be mature and successful.

\section{Chinese evaluation tradition}

The unique Chinese tradition on life style is formed by the closed geography and suitable agro-climatic conditions (Yue, 2001). As the basic social form, "Family-State Integration" 510 
reflects Chinese typical social existence (Liu, 1993). It means that family extends its functions to a country while country runs its responsibilities as a family. From moral to policy, individual to society, the idea of "Family-State Integration" ties Chinese culture and educational tradition to policies deeply and directly. As the new curriculum develops, the conflict between the new and old ideas about evaluation is inevitable. Apparently, there are four main negative aspects exposed in Chinese evaluation tradition.

\subsection{Utilitarian evaluating aim}

In order to break the barrier of hereditary system, Chinese educational tradition aims to cultivate students from different social hierarchy to be officials of government (Wang, 1999). It is an effective shortcut for students to raise their social hierarchy and become rich (Confucius, 551-479BC). As such, the learning motivation of students is not to get knowledge but social hierarchy and power ( $\mathrm{Su}, 2009)$. And the examination system ties school education to social policies tightly. With the time flying away to today, the negative characters of this traditional aims are following (Yue, 2001). Firstly, it drives people to pursue the simple testing scores and prevents people from knowing and accepting the modern educational views to promote students' round development. Secondly, it influences people to ignore the importance of professional and technical education and then lead to the disequilibrium in the basic educational structure. The last but the noticeable one is that traditional education aims to force individual to quench his/her creative desires and personal development but obey the requirement from top or collective.

\subsection{Utilitarian evaluating content}


The content of Chinese education serves the principle of "Family-State Integration". It focuses on the basic rules, regulations and etiquettes as well as the spirits among the social relations (Fan, 1992). Loyalty, filial piety, benevolence and righteousness are the core contents for students to learn and obey (Liang, 1921). Any new idea or little modification on these contents would be punished or suppressed. In the old schools, the contents of teaching mostly focused on the political and article subjects and looked down the importance of scientific knowledge ( $\mathrm{He} \& \mathrm{Hu}, 2005)$. Such of one-sided educational content disturbs students heavily to learn kinds of knowledge to reach physical and spiritual health. Furthermore, China is a great multi-culture \& nation country, the standardized and institutionalized educational contents always concern less on the characters of different territorialism and nationalities (Ding, 1992). When teaching contents are related to an official selection, it is apparent to observe that science, culture and academic freedom are limited heavily to make further progress. However, the personalities and creativity of individuals are also ignored during the traditional school training coherently.

\subsection{Utilitarian evaluating roles}

Chinese education has been limited so much by the impact of the "Family-State Integration". Conducted by the traditional social form, students must obey the teacher's instruction without any personal view (Zhu, 2002). Furthermore, students mustn't learn other classic texts except the ones that their teacher point at to them. That fulfills the governors' dream to control people's mind but leads to the disappearance of student creation and the great gap among teachers, students and scholars. There is a Chinese old saying reflecting the authority and hierarchy of student-teacher relationship like that one should respect one-day's teacher as his 512 
father for life. Without equal communication and understanding, the basic responsibilities of students in the school are obedient, industrious and clean-living ( $\mathrm{He} \& \mathrm{Hu}, 2005)$. What is more that examination is the most important way for students to climb up to the higher social hierarchy. Teachers should accept any behaviour whatever, so long as the students can pass the examination. How sorrow it is for students, teachers and Chinese education to meet such a loose Student-Teacher relationship in the classroom.

\subsection{Utilitarian evaluating methods and process}

"The people needn't understand the meaning but obey to follow a path of action" ( Confucius, 551-479BC). It shows that the key of Chinese policies is to control people's mind. Influenced by policies, the teaching methods of educational tradition are used to train students rote learning and test-taking abilities (Wang \& Chen, 2008). Normally, in the classroom, teachers always instruct the knowledge which is needed for test while students take the notes and recite the knowledge with less understanding. Much more, in order to pass the national examination, opportunity, irregularity and academic corruption are thought always by some people to damage the social morals (Zhao, 2009). As we know, it is the time of knowledge economy and various competences are the cores for a nation to lead to advance in the world. The spirit of education is to cultivate people's competences as independence, freedom and creativity. But Chinese traditional teaching methods are the right bonds to restrict students' innovation and hands-on abilities, which is far away from the social need for the multicompetence elites. 
Both history and modern are existed together while tradition and innovation are tied to each other closely (Ding, 1992). The limitations of Chinese educational tradition calls an innovation coming. Indubitably, it is the duty of Chinese Evaluation reform.

\section{Chinese Evaluation Reform}

Pinpointing the causes of the educational tradition problems on aim, content, method and student-teacher relationship, since 2001, Chinese evaluation reform aimed to (1) change knowledge-centered instruction in the classroom into learning attitude and modes cultivated to learn how to learn and how to be; (2) change the subject-oriented of curriculum structure into subject- integrated to meet the different needs of regions and individual development; (3) change the mechanical training and rote learning into collaborative, creative, problem-oriented learning to promote students' abilities to collect new knowledge, analysis new problems and cooperate with others; (4) change test-oriented and summative evaluation into formative and authentic evaluation to improve teachers' teaching and students' learning practice; (5) Change single centralized curriculum from into three levels of decentralization from state, locality and school to enhance their participation and adaptability into course management (Chinese Ministry of Education, 2001).

Undoubtedly, this reform is a great progress to promote evaluation tradition to stride into modern education. But China is a government-led country while course-centralized is significant. "New evaluation reform is an action of both government and specialists, which integrate the power from policy and theory to meet an open, reasonable and democratic Chinese education" (Zhong, 2005). When the government and the specialists push the new 
evaluation reform to implement actively, the sensible limitations of the Reform have been brought into evaluation practice as following.

\subsection{The suspending evaluating aim}

As we all know, knowledge is the core and base of school education (Wang, 2006). In context of Chinese evaluation reform, it is said that the highlight of this innovation is to emphasis on three-dimensional aim: knowledge, learning methods \& process, attitude \& emotion (Zhang, 2008). But a serious deficiency is very clear that three-dimensional aim doesn't point at the relationship and position respectively among three aims. And what's more, it scatters and weakens the base and spindle position of knowledge in school education (Li, 2008). As a result, the three dimensional aims brings reduced knowledge \& skill, haphazard learning methods \& process and formalistic emotion, attitude \& value into classroom. Even though the teachers with enough teaching experience and competences would be puzzled to integrate the three aims into practice successfully. As such, it is normal to observe many in-service teachers guiding students to accept the emotion, attitude and value education separately and mechanically without integrating the knowledge, skills and methods into specific and real situation $(\mathrm{Wu}, 2005)$.

\subsection{The suspending evaluating content}

Textbooks are the basic evaluating materials in the classroom (Xu, Zhuang \& Yu, 1998). Arguing that an important change in Chinese evaluation reform may be to integrate textbooks, teachers and students into curriculum resource (Chinese Ministry of Education, 2001), such as it is a great progress to break textbook-oriented and promote teachers \& students to create open, interactive and flexible learning environment positively. Wang (2006) critiqued the 
tendency that " when there are so many curriculum resource integrated into classroom, it is easy for teachers to ignore the importance of textbook but balance kinds of resource to cater to reform ideas". In fact, it is meaningful to change textbook-oriented instruction to textbookused learning in the classroom. But how to use textbook well and balance the importance of other curriculum resource, which are related to teaching beliefs, experience and competences, are urgent for teachers to clear and act. Furthermore, how to edit sets of high quality textbooks, which match to the need of local educational culture and tradition, are urgent for school to cultivate a group a high qualified in-service teachers.

\subsection{The suspending evaluating roles}

Students' subjectivity is an outstanding reform object for reformers bring forth in school education specially (Wang, 2009). It is a good phenomenon. But during the process putting the new idea into practice, it is found that the teachers don't know how to carry on their duties correctly while students don't know how to gain the knowledge and show the superficial subjectivity in the classroom $(\mathrm{Wu}, 2005)$. Actually, the conception of subjectivity in evaluation reform means the personality of human being (Zhong, 2005). Unluckily, some inservice teachers who are lack of responsibility and understanding the spirit of evaluation reform said that it was good to carry on New Evaluation reform for that they would be relax to ask students to learn by themselves instead of teaching them so hard (Feng \& Li, 2010). In the school, the student subjectivity should be instructed by teachers with clear learning assignments and contents. It depends on the teacher's cultivation in long planned term. Accordingly, teacher should conduct an equal teacher-student relationship to avoid the 
negative learning environment as students speaking out the topic loudly but inefficiently while teachers listening without any instruction in the classroom.

\subsection{The confliction of evaluating methods and process}

It is approved generally that the new evaluation reform advocates various learning styles as self-directed learning, collaborated learning and explored leaning (Li, 2006). But the news from practice is not good. For example, Guo (2003) pointed that students' subjectivity was highlighted too much to ignore or deny the importance of teacher instruction and language learning in the classroom. Obviously, such of the teaching and learning process is far away from teachers' educational beliefs that was growing since they were young. With the gap between new reform ideas and real education action enlarging, teachers only copy more the form of new learning methods negatively than understanding its real meaning actively ( $\mathrm{Wu}$, 2003). And then there is a confliction existed between various learning styles and practical learning process. In fact, the key to carry on various learning methods is kinds of knowledge and learning contents that are imparted by teachers primarily. Furthermore, language is the important medium for people to gain knowledge (Wang, 2006). Teacher instruction can bring the language function effectively into learning activities to promote students to gain amount knowledge in limited time. On the base of teacher instruction, a teacher can not only provide students the basic knowledge effectively but also integrate kinds of learning methods into various learning activities successfully during the teaching process.

By now, it is clear that with a good will, Chinese new evaluation reform hopes to change the negative aspects of educational tradition to match to the needs of modern education. But many educators pointed at the problem of reform as that "there are so many theoretical slogan, 
concepts and experiences except the idea how to relate theories to practice in Chinese education nowadays" (Wu, 2009). Whether we admit it or not, it is a truth that there is a great gap between reform ideas and classroom practice during the implementation process of new evaluation reform in China.

\section{The Gaps among policy, theory and practice}

"Crisis leads to reform and reform blooms puzzles" (Zhong, 2005). Same to new evaluation reform, it is also the result of the crisis of educational tradition. Meanwhile, there are so many difficulties come out from the process of reform. In order to meet a democratic, scientific and modern education, the advocators viewed that Chinese new evaluation reform was a collaborative action of government and specialists. Government was the holdback of reform to be successful while specialists were the designers and leaders of reform walking to success (Zhong, 2005). If we go into the problems and difficulties produced during the reform process in more detail, we can see that kinds of difficulties are taken into two principle gaps.

\subsection{Gap 1: Educational Policies and classroom practice}

China is a government-centered country and educational structure is endowed the significant centralized nature. The new evaluation reform can derive to the choice and decision of government. As a national educational evaluation reform, the CPC Central Committee involved all social powers including Ministry of Education, levels of local governments into evaluation reform to implement and promote the educational essentials decided by Central Government. Consequently, from top to down, levels of governments issued kinds of educational political documents to improve teacher training, evaluate teacher professional quality. Actually, it is clear that China has been successful to drive a great evaluation reform 518 
to each corner in a short time. At the same time, an advisory report submitted to the Ministry of Education shows that most schools did not carry out the school-based activities and general practical courses required by the plan of national curriculum implementation (Wu, 2009).

\subsection{Gap 2: Educational theory and classroom practice}

Mentioned before, the core of Chinese culture and tradition is "Family-State Integration", which effects Chinese education deeply till today. With the progress of "open-Gate-to-World", kinds of foreign theories as behaviorism, humanism, constructivism, etc. flood into China and lead to different theoretical views in Chinese education field. However, combined the educational tradition, so many specialists with their different theoretical background are involved into the great evaluation reform to improve Chinese educational situation positively. One of most important duties for specialists is to explain the educational policies, actions and standards for society and school to guide evaluation reform walking to success. But when all of specialists explain educational policies respectively by their own theoretical position, most teachers are always confused by these contradictory or opposite explanations to carry on reform practice in the classroom smoothly.

\subsection{The reflection of two gaps: teachers' attitude}

Bringing the idea of evaluation reform to practice, teacher is the final operator. In order to guarantee the smooth implementation of evaluation reform, the basic principle of reform proposed that each teacher must accept new curriculum training before taking a job. But such of the basic principle doesn't work well as foreseeing. To the contrary, a lot of in-service teachers didn't accept the new ideas of curriculum or put them into practice. A big scale survey shows that $25.2 \%$ teachers adapted to new evaluation reform totally, while $72.8 \%$ 
teachers have difficulties to adapt (Ma \& Tang, 2004). Why do the teachers hold the negative attitude to the new evaluation reform? There are three reasons to be discussed. Firstly, evaluation reform shakes teachers' educational beliefs directly and lead to the great crisis of teaching emotion (Yin \& Li, 2007). Secondly, teachers have to pay for more energy and time to response and adapt to evaluation reform than before (Cao \& Lu, 2003). Thirdly, various training materials from different educators are imparted to in-service teachers by trainers with different levels of proficiency. As a result of these reasons above, the negative attitude of teachers are formed to against the new evaluation reform.

\subsection{The reflection of two gaps: theory of communication}

Trace the two gaps to their source, we can find that the most important reason is a lack of communication between top and bottom as well as theory and practice. Actually, evaluation reform is a topic action. Whether it is feasible or not, it should be proved by all of the members who has involved themselves into this movement equally. Everyone can contribute his/her own views without any enforcement from outside to promote other people to choose positive or negative support, and then the ideas supported by public can be carried on in the community and be obeyed by all of members to reach the harmony and steady development (Habermas, 1984). Looking back, we can see that both Chinese educational tradition and evaluation reform involve in-service teachers into the practical action but reject to touch their real inlet educational views. Meanwhile, both of them regard school as a special area to produce the qualified production to match to the need of society. For that they are lack of the communication with in-service teachers, it is natural to produce so many kinds of negative response in teacher groups (Apple, 1992). However, communication is not an obligatory but a 520 
creative action to collaborate top and down to promote a humanize world. But how to communicate between top and down? Firstly, sincerity, truth and right are basic conditions for both sides; Secondly, top with down challenges the same educational issues to propose the ideas or views respectively; Thirdly, according to the current, realistic and specific educational situation, all of the communication should reflect the people's will (Habermas, 1984).

\section{The way to communication}

Chinese education is based on Chinese traditional culture of "Family-State Integration". During the practice of evaluation reform, Chinese education encountered a lot problems including aims, contents, methods and student-teacher relationship. Exploring the reasons of the problems, it has been realized by people that without communication between top and down, any reform ideas would challenge the core values held by teachers regarding the purposes of world (Fullan, 2001). Among the core values, belief is the key factor to be researched to touch the teacher's inside world (Munby, 1982; Clark and Peterson, 1986), and then lead the evaluation reform to success.

\subsection{Teacher beliefs}

Belief is the people's personal philosophy, which consists of a group of consistent, coherent and adequate beliefs (Price, 1969; Rokeach, 1973; Ferre, 1988). Any change in beliefs would challenge the core values held by individuals regarding the purposes of world (Fullan, 2001). And teacher beliefs are a powerful philosophy for teachers to translate their experiential worlds of the classroom into a unique view of what constitutes good teaching and learning since the teacher was childhood. As a complex cultural environment (Geertz, 1973; Lieberman, 1992), a classroom is a right place for teacher and students to negotiate, explore, 
and assemble personal knowledge, beliefs and interpretations one another through ongoing epistemological processes (von Glasersfeld, 1987). According to the literature review about teacher beliefs, most researchers revealed that teacher beliefs were key to the success of the current reform movement in education. Failure to take into account teacher beliefs would result in the continual return of reform efforts (Battista, 1994; Cuban, 1990; Civil, 1993; Vacc \& Bright, 1999; Fullan, 2001). The reason is that beliefs are based on evaluation and judgment and play a critical role in defining behavior, organizing knowledge and imbuing attitude consciously or unconsciously (Nespor, 1987; Pajares, 1992; Borg, 2001).

\subsection{Theoretical support}

Even though the aim of evaluation reform is to improve the limitation of educational tradition, it is in the sense not to force but encourage and allow teachers to communicate with reformdesigners about their own practical ideas in the classroom, and then to strengthen the link between top and down. However, it is the key to find a way to communicate with teachers and then influence their beliefs. The Onion Model developed by Korthagen (2004) can provide the theoretical support. It shows that there is a very important assumption behind the model. It is that the outer levels (environment, behavior) can influence the inner levels (competence, beliefs, world view). Meanwhile, the inner ones can determine and impact on the outer ones. For example, in education field, environment (policy makers, training institutions) can influence the behaviors (teaching and learning activities), and then influence the inner levels as competence (skills, knowledge) and beliefs. Equivalently, teachers beliefs impact on their teaching behavior via their teaching competence to response the environment. As such, from the perspectives of epistemology, beliefs refer to knowledge, learning, and the kind of 522 
evidence acceptable when making claims about what people have learned. These beliefs, though tacit, frame our ways of thinking about such questions as: What is considered valid knowledge in a given subject, profession, or discipline? Who is considered authoritative? How does one move from novice to expert within a field of study? These are, essentially, the basis of one's philosophy of knowledge.

\subsection{Teacher evaluation beliefs}

Mentioned above, teacher beliefs are always related their personal educational philosophy to the whole teaching process including preparation, instruction, practice, homework and evaluation. Drawing out from the huge literature reviews about teacher's educational beliefs, we focus on the key driving element of teaching process---evaluation to examine the possibility and validity of communication between top and down. Furthermore, evaluation is also one of most important content for evaluation reform to improve (Ministry of Education, 2002).

As we all know that inherent in the idea of evaluation is "value". When we evaluate, what we are doing is engaging in some process that is designed to provide information that will help us make a judgment about a given situation, taking into account such ideas as objectives, goals, standards, procedures, and so on. In particular, in a classroom, teacher's evaluations are usually done in the context of comparing worthiness, appropriateness, goodness, validity, effect, etc. All of these value judgments are relate to teacher beliefs.

Based on belief framework that relies on mental constructs to form an individual's philosophy by logical, rational data in life, teachers' philosophy knowledge is shaped since childhood (Borg, 2004) and showed during the evaluation processes as following: What is valid and 
valuable knowledge to be evaluated; Who is the authority in evaluation activities; Why should the teacher keep all of his/her ideas about evaluation during the teaching and learning process (aim); When is the right time to carry out the evaluation procedure; how to adopt the effective and appropriate strategies and forms to promote his/her professional development and student learning achievement (Shulman, 1986; Grossman, Wilson, \& Shulman, 1989; Kagan, 1992; Beattie, 1995). Obviously, all of these questions focus on the limitation of educational tradition and evaluation reform from aim (why), content (what), time (when) to method (how) as well as teacher-student relationship (who).

With the understanding of belief framework and the guidance of "Onion Model", Chinese evaluation reform could elaborate a useful solution of the confliction between top and down about evaluation standards. Given that "Onion Model" concerns on both observed and unobserved factors that work on the learning activities in the classroom. As such, we could depart Onion Model into two aspects. One is that we could confirm the environment and behavior during teachers' evaluation process. From these observed elements, we can deduce how much the teacher response to the environment(political evaluation standards, training) in the classroom. The other one is that we could explore teachers' unobserved beliefs and competences via interviews and questionnaires. All the data collection could help us to analysis and explore teachers' personal philosophy about evaluation in the classroom. So far, all of observed and unobserved information about teacher evaluation beliefs could be put together to find a feasible way to communicate between top and down as well as contribute the New Evaluation reform in China.

\section{Conclusions}


Aim, content, method and student-teacher relationship are the core elements for education in the world. They are also the keys for all of education reforms to change traditional negative aspects to the positive ones to meet the need of modern society. Similar to China, the new evaluation reform have paid for great endeavors to clear the barriers on the way of educational progress since 2001. Ten years has gone by! Chinese education makes great success while there are so many problems produced during the evaluation reform.

When we threw ourselves into these complex problems, we found that Chinese traditional culture, which is related "Family-State Integration" and "Centralization of government-led", influences Chinese education directly and deeply till today. Without the communication between top and down, during the process of evaluation reform, a strange phenomenon is following: designers issued reform policies, teachers accepted reform training and students followed the same teaching rhythm as before.

How to communicate? It is clear that we couldn't change Chinese political system and culture education. By far, the urgent educational issue has been proposed to find a feasible way to promote communication between top and down. With the support of "Onion model" theory and belief frame, we focused on the key driving element-evaluation in the teaching process to confirm the importance of individual beliefs as well as propose an effective way for communication between top and down.

\section{References:}

Apple, M. W. (1990). Ideology and Curriculum. New York: Routledge, 2nd edition. Political science with state power and legal knowledge. Ma, H.M. (interpretation,1992). East China Normal University (Educational Science Edition), 02. 
Battista, M. T. (1994). Teacher beliefs and the reform movement in mathematics education. Phi Delta Kappan, 75(2), 462-470.

Beattle, M. (1995). New prospects for teacher education: narrative ways of knowing teaching and teacher learning, Journal of Educational Research, 37(1), 53-70.

Bonoti, F., \& Metallidou, P. (2010). Children's judgments and feelings about their own drawings. Journal of Psychology, 1, 329-336.doi:10.4236/psych.2010.15042

Borg, M. (2001). Teachers' beliefs. ELT Journal, 55(2), 186-188.

Borg, M. (2004). The apprenticeship of observation. ELT Journal, 58(3), 274-276.

Cao, T. S. \& Lu, N. G. (2003). Resistance and collaboration: teacher change in the situation of evaluation reform. Journal of curriculum, teaching material and method. 01, 75-79.

CHI Conference (2009). Guide to a successful HCI archive submission. URL (last checked 15 May http://www.chi2009.org/Authors/Guides/ArchiveGuide.html

Chinese Ministry of Education (2001). The notice about trying the essentials of curriculum reform out in China.

http://www.moe.gov.cn/publicfiles/business/htmlfiles/moe/moe 711/201001/xxgk_78380.htm 1)

Chinese Ministry of Education (2002). The notice about promoting innovation of evaluation and testing system actively in primary school and middle school http://www.moe.gov.cn/publicfiles/business/htmlfiles/moe/moe_441/201001/xxgk_78509.htm $\underline{1}$

Civil, M. (1993). Prospective elementary teachers' thinking about teaching mathematics. Journal of Mathematical Behavior. 12,79-69.

Clark, C. M. and Peterson, P. L. (1986). Teachers' thought processes. In: Wittrock, M.C. (Ed) Handbook of Research on Teaching. New York: Macmillan, 255-96.

Cohn, E., \& Geske, T. (1990). Ch. 7: Production \& cost functions in education. In The Economics of Education. New York: The Free Press, 159-210.

Confucius(551-479BC). The Analects of Confucius. http://www.chinakongzi.com/2550/eng/ Cuban, L. (1990). Reforming again, again, and again. Journal of Educational Researcher, 19(1), 3-13. 
Ding, G. (1992). Some arguments about educational tradition and innovation. Journal of Chinese Education, 02, 05-08.

Fan, H. (1992). The historical construction of Chinese ethical spirits. Nanjing: Jiangshu People's Publishing House. 13.

Feng, Y. H. \& Li, J. (2010). The reflection and enlightenment about problems of New Curriculum Reform on the base of ecological theory. Journal of New Curriculum Research. 01, 16-18.

Ferre, F. (1988). Philosophy of Technology. Prentice Hall, New Jersey.

Fullan, M. (2001). The new meaning of educational change. New York: Teachers College Press. 45,44 .

Geertz, C. (1973). The interpretation of cultures. New York: Basic Books.

Gregoire, M. (2003). Is it a challenge or a threat? A dual-process model of teachers' cognition and appraisal processes during conceptual change. Journal of Educational Psychology Review, 15(2), 147-179. 